\title{
Microstructure and properties of stoneware clay bodies
}

\author{
A. J. FLYNN AND Z. H. STACHURSKI* \\ Department of Engineering, FEIT, Australian National University, Canberra, ACT0200, Australia
}

(Received 24 October 2005; revised 19 June 2006)

\begin{abstract}
Raw clay materials manufactured for stoneware use are typically compounds of kaolins, silicas and feldspars. Two stoneware clay materials examined here were chosen because each is representative of the range of manufactured clay bodies. Samples were fired in an oxidizing atmosphere to a range of temperatures between $\sim 1000$ and $1300^{\circ} \mathrm{C}$. Sample dimensions, density, porosity and mechanical properties under compression were measured as a function of firing temperature. Thin sections, showing particles and their relationship to pore/void structures, were prepared, recorded under scanning electron microscopy (SEM), and analysed. The observed changes in microstructure can be related to previously described metamorphic and micro-eutectic reactions and a gradual sintering process. Indications of changes to apparent porosity are further amplified by measured changes of mechanical properties. The modulus of elasticity increases with reduction in porosity to a point at which porosity ceases to be the principal determining factor. The critical Griffith's crack length, calculated from fracture-strength measurement, exhibits a similar trend. The onset of these changes coincides with a significant increase in sealed porosity and with the microstructural metamorphosis as revealed by SEM.
\end{abstract}

KEYWORDS: kaolin, silica, feldspar, porosity, microstructure, elastic modulus, compressive strength.

While extensive research has been conducted into industrial ceramics (i.e. high-temperature refractory or brick materials), there has been little, if any, examination of structure-property relationships in non-industrial clays. The implications for structureproperty relationships of changes in composition, firing temperature and distribution of particles have hitherto been observed only on an empirical basis. In this study we report on experimental results and analysis, which allow the comparison of such data with those contained in the already extensive body of literature relating to industrial clay-based ceramic materials. Stoneware clay is a material of great complexity. It is manufactured by mixing (in a wet state) finely ground ingredients of kaolin,

\footnotetext{
* E-mail: zbigniew.stachurski@anu.edu.au

DOI: $10.1180 / 0009855064130218$
}

feldspar and silica with or without various additives, to produce a 'body' possessing the property of plasticity in its wet state, and subsequently drying and heating to high temperatures $\left(\sim 1000-1300^{\circ} \mathrm{C}\right)$.

It appears from our experience and an exhaustive literature search that the relationship between the properties of fired stoneware clays and their microstructures, dictated by the distribution of particles sizes in raw materials, is to a large extent uncharted territory. In particular, we measured the various relevant properties that combine to affect final properties and inquired as to whether or not a point exists at which, or beyond which, optimal strength is achieved.

Our study shows some similarity to investigations carried out recently by Bauluz et al. (2004), in which mineralogical and textural changes produced in carbonated clays for brick making were reported. 
The transformations that take place during the firing of raw materials determine the final properties of the ceramic products, and therefore an understanding of the microstructural changes is important in understanding structure-property relationship.

\section{THEORETICAL BACKGROUND}

\section{Density and porosity}

The volume of a ceramic body comprises solid substance, open voids (which are articulated and connected to the outside), and closed pores (sealed). Therefore, the volume of the body can be divided into three parts:

$$
V_{\mathrm{b}}=V_{\mathrm{s}}+V_{\mathrm{op}}+V_{\mathrm{sp}}
$$

where: $V_{\mathrm{b}}$ is defined by the external dimensions, $V_{\mathrm{s}}$ is the volume occupied by the solid substance only, $V_{\text {op }}$ is the volume occupied by the open pores, and $V_{\text {sp }}$ is the volume occupied by the sealed voids. Given the mass of the solid substance, $m_{\mathrm{s}}$, the density of the body, $\rho_{b}$, is defined as:

$$
\rho_{\mathrm{b}}=\frac{m_{\mathrm{s}}}{V_{\mathrm{b}}},
$$

and the density of the solid substance is defined as:

$$
\rho_{\mathrm{s}}=\frac{m_{\mathrm{s}}}{V_{\mathrm{s}}}
$$

In general, $\rho_{\mathrm{b}}<\rho_{\mathrm{s}}$, if $\left(V_{\mathrm{op}}+V_{\mathrm{sp}}\right)>0$, and $\rho_{\mathrm{b}}=$ $\rho_{\mathrm{s}}$, if $\left(V_{\mathrm{op}}+V_{\mathrm{sp}}\right)=0$. We define the following ratios as the volume fraction of the open pores, and that of the sealed pores, respectively:

$$
\begin{gathered}
\mathrm{v}_{\mathrm{op}}=\frac{V_{\mathrm{op}}}{V_{\mathrm{b}}} \\
\mathrm{v}_{\mathrm{sp}}=\frac{V_{\mathrm{sp}}}{V_{\mathrm{b}}}
\end{gathered}
$$

From equations 1 to 5 , the following relationship can be derived:

$$
\frac{\rho_{\mathrm{b}}}{\rho_{\mathrm{s}}}+v_{\mathrm{op}}+v_{\mathrm{sp}}=1
$$

Assuming that water can fill all of the open pore spaces, then the so-called apparent porosity of the ceramic body is defined as follows (Singer \& Singer, 1971):

$$
\operatorname{AP}(\%)=\frac{\text { wet weight of sample }- \text { dry weight }}{\text { dry weight of sample }} \times 100
$$

where: 'dry weight' is the weight of sample without any water (moisture), and 'wet weight' is the weight of sample with open pores completely filled with water. The dry weight of the sample determines the mass of the solid substance, $m_{\mathrm{s}}$. The increase in the weight of the wet sample is assumed to be due to water ingress through open pores. Since water content $=v_{\text {op }}$, then the volume fraction of open pores can be calculated from:

$$
v_{\mathrm{op}} \cong \rho_{\mathrm{b}} * \frac{\mathrm{AP} \%}{100}
$$

If the solid density, body density, and open porosity are known, then from equation 6 the amount of sealed porosity can be predicted to be:

$$
v_{\mathrm{sp}}=1-v_{\mathrm{op}}-\frac{\rho_{\mathrm{b}}}{\rho_{\mathrm{s}}}
$$

If the solid substance is made up of a number of different constituents, then the mass of the solid is the sum of the masses of the individual constituents. The overall density of the solid, in the absence of chemical interactions, is predicted by the simple law of mixtures (Holliday, 1967):

$$
\rho_{\mathrm{s}}=\rho_{1} v_{1}+\rho_{2} v_{2}+\rho_{3} v_{3}+\ldots \rho_{\mathrm{n}} v_{\mathrm{n}}=\sum_{i=1}^{n} \rho_{\mathrm{i}} v_{\mathrm{i}}
$$

where: $v_{1}, v_{2}, v_{3} \cdots v_{n}$, represent the volume fractions of the individual constituents respectively, and $\rho_{1}, \rho_{2}, \rho_{3} \cdots \rho_{n}$, are the corresponding densities.

\section{Modulus of elasticity}

The elastic modulus is a function of both matrix composition and porosity. To a first approximation, the dependence on composition can be predicted by a simple law of mixtures. Thus:

$$
E=E_{1} \mathrm{v}_{1}+E_{2} \mathrm{v}_{2}+\ldots+E_{n} \mathrm{v}_{n}=\sum_{i=1}^{n} E_{\mathrm{i}} \mathrm{v}_{\mathrm{i}}
$$

where: $E_{1}, E_{2} \cdots E_{n}$ are the elastic moduli of individual components. If only two phases are considered, the first solid and the second is assumed to be void with zero elastic modulus, then the relationships for the porous body can be represented (Kunori \& Geil, 1980) as:

$$
\frac{E_{\mathrm{b}}}{E_{\mathrm{o}}}=\frac{1-p}{1+p k}, \text { where } k=\left(\frac{8-10 \mathrm{v}}{7-5 \mathrm{v}}\right)
$$

where: $E_{\mathrm{o}}$ is elastic modulus of the matrix without pores, $E_{\mathrm{b}}$ is elastic modulus of the body with pores, 
$p$ is total porosity, and $v$ is Poisson's ratio of the matrix. Different relationships for porous bodies were proposed by several authors (Helmuth \& Turk, 1966; Sammis \& Ashby, 1986; Brandt et al., 1978). Specifically, Helmuth and Turk proposed:

$$
\frac{E_{\mathrm{b}}}{E_{\mathrm{o}}}=(1-p)^{3}
$$

A plot of $E_{\mathrm{b}} v s .(1-p)^{3}$ should extrapolate to the ultimate modulus, $E_{\mathrm{o}}$, at $p=0$. Similarly, from equation 12, a plot of $E_{\mathrm{b}} v s .(1-p) /(1+p k)$ should also extrapolate to $E_{\mathrm{o}}$ at $p=0$.

\section{Compressive strength}

The compression failure of brittle samples has been described by Kendall (1978), who showed that the compressive stress required to split a columnar specimen containing a vertical crack is given by:

$$
\sigma_{\text {split }}=\frac{\sqrt{2 / 3}}{(1-w / d)} \sqrt{\frac{E G_{\mathrm{Ic}}}{d}}
$$

where: $d$ is the specimen width, $w$ is the width of the compression platen, $E$ is the specimen's modulus of elasticity, and $G_{\mathrm{Ic}}$ is the critical strain energy release rate (fracture toughness). The equation predicts the compressive strength to increase with the specimen elasticity and fracture toughness, and its dependence on geometry, but not on crack length. The apparent difficulty with equation 14 for $w=$ or $>d$, a common geometry for most compression tests, has been resolved by Ashby \& Hallam (1986) who considered a multitude of cracks and voids from which winged cracks can initiate and grow. When loaded in compression, the cracks grow and interact with other growing cracks, ultimately leading to coalescence and finally to catastrophic failure. They showed that the initiation condition, for the case of simple compression, was given by:

$$
\sigma_{\mathrm{f}}=\frac{\sqrt{3}}{\sqrt{1+\mu^{2}}-\mu} \sqrt{\frac{E_{\mathrm{b}} G_{\mathrm{Ic}}}{\pi a}}
$$

where: $\sigma_{\mathrm{f}}$ is the fracture initiation stress, $a$ is the critical length of a crack in the plane of maximum shear traction, $E_{\mathrm{b}}$ is the modulus of elasticity of the body, and $\mu$ is the friction coefficient for sliding crack faces. In equation 15 there is crack-length dependence. Therefore, sudden brittle fracture is predicted once the initiation condition is satisfied.

\section{MATERIALS AND METHODS}

\section{Experimental raw materials}

Sufficient quantities of two manufactured stoneware clays, denoted as Body A and Body B, were obtained from Clayworks, Dandenong, Victoria, Australia. The composition of the stoneware clays were: (1) Body A - kaolin, feldspar and quartz; and (2) Body B - kaolin, feldspar, quartz and with small additions (a few percent) of goethite, $\mathrm{FeO}(\mathrm{OH})$. The precise ratios were not available. At the same time, small quantities of the raw materials in an unmixed state were also purchased for mineral identification. The X-ray diffraction (XRD) identification of three of the raw materials, and quantitative particle-size distribution are reported below.

From observations of thin sections by optical microscopy, and from investigation of conventions followed by manufacturers in Australia, we estimated the volume fractions of the initial constituents to be in the range (1) kaolin: $0.60-0.70$, (2) feldspar: $0.20-0.15$, and (3) quartz: $0.20-0.15$. The essential differences between Bodies $\mathrm{A}$ and $\mathrm{B}$ lie in the differences between the proportions of kaolin/ feldspar/quartz, and in particle-size distributions. These are reflected in finished, fired surface qualities: $\mathrm{A}$ is white whereas $\mathrm{B}$ is fired darker and shows a coarser surface than A.

\section{Sample preparation and firing}

Samples (in wet state) were extruded in $180 \mathrm{~mm}$ lengths through a die with a circular aperture of $20 \mathrm{~mm}$ diameter and a $1^{\circ}$ reducing taper. $180 \mathrm{~mm}$ was chosen to reduce or eliminate wasting or necking due to stretching under the sample's own weight prior to cutting off. The extruder barrel was washed at the completion of the extrusion of each stoneware clay body.

All extruded samples were fired in an oxidizing atmosphere to $\sim 1000^{\circ} \mathrm{C}$ in one firing in a temperature-controlled electric kiln. The firing cycle followed a temperature increase rate of $60^{\circ} \mathrm{C} / \mathrm{h}$ to $300^{\circ} \mathrm{C}$, followed by $150^{\circ} \mathrm{C} / \mathrm{h}$ to completion. The kiln was allowed to cool normally to $200^{\circ} \mathrm{C}$ before opening. After initial firing, all sets of extrusions were sawn to $36 \mathrm{~mm}$ sample lengths by a water-cooled, diamond-saw-blade cutter with a movable bed. Altogether, 180 test samples of each body were made, allowing a choice of five for each of the subsequent 10 oxidation firings. 
Next, the samples were packed in a systematic $\mathrm{ABABAB}$ order to spread any localized variations in temperature/heat work more equably across the whole sample-body range, and fired to higher temperatures. Standard Orton Cones, manufactured by the Edward Orton Jr. Ceramic Foundation, were chosen for use in all kiln firings associated with this project (Orton, 1994). The cones were placed on the centre line of each shelf $100 \mathrm{~mm}$ back from the leading edge. Twelve firing temperatures were chosen: Orton Cones $06,04,03,01,2,4,6,7,8,9,10$ and 11 .

\section{Sample dimensions and weight}

The dimensions of all samples were measured using vernier callipers capable of accuracy to $0.01 \mathrm{~mm}$. The length of the cylinder was measured once; the diameter in three places, and averaged for each sample. The expected relative error in length is estimated as $0.01 / 36$ $=3 \times 10^{-4}$, and in diameter as $0.01 / 20=5 \times 10^{-4}$. From these measurements the volume of each sample was calculated, with the relative error calculated as $2 \Delta R / R+\Delta L / L=1.3 \times 10^{-3}$.

All samples were dried for $24 \mathrm{~h}$ at $200^{\circ} \mathrm{C}$ and weighed immediately on removal from the drying oven using scales (Mettler Model AB204). Wet weight was measured by first boiling samples suspended and immersed in water for $1 \mathrm{~h}$, then allowing the samples to cool naturally for a further $23 \mathrm{~h}$ while completely immersed in the water in which they were boiled. Each sample was removed from water, rolled on absorbent paper to dry the surface and weighed.

\section{Particle-size distribution}

Samples were prepared using a $0.05 \%$ Calgon-inwater deflocculant with sample density of $2.65 \mathrm{~g} / \mathrm{cc}$ and liquid density $0.9944 \mathrm{~g} / \mathrm{cc}$. The sedimentation rate was measured using a SediGraph 5100 instrument for particle-size distribution within the range $0.1-60.0 \mu \mathrm{m}$. Particles in the range $60-2000 \mu \mathrm{m}$ were measured using a column sediment analyser.

\section{SEM imaging of thin sections}

Thin sections of each fired sample were cut using a diamond saw to a thickness of $\sim 1.2 \mathrm{~mm}$. The sample face was hand ground using P800 wet and dry papers to minimize irregularities within the cut surface. The sample was dried and attached to a standard petrology slide using Petropoxy that had been first applied and absorbed into the porous structure before slide attachment. Using standard $15 \mu \mathrm{m}$ alumina oxide grit, each sample was then reduced to $35 \mu \mathrm{m}$ average thickness on the laboratory's Logitech LP30 lapping and optical polishing equipment. The sample was then further polished and reduced in thickness using a tin lap with $2.5 \mu \mathrm{m}$ diamond paste and oil, with the final polished $30 \mu \mathrm{m}$ finished on Pellon cloth with $1.0 \mu \mathrm{m}$ diamond paste and oil.

Using the facilities of the ANU's Electron Microscopy Unit, $30 \mu \mathrm{m}$ thin sections of each sample were carbon-sputter coated. Samples were viewed on the Cambridge 360 instrument, using SEM backscatter mode at $\times 800$ magnifications. Five randomly selected regions from each sample were imaged and recorded both electronically and photographically.

The same carbon sputter-coated thin sections of each sample were subjected to analysis using an X-ray probe on the Unit's JEOL 6400 instrument.

\section{Measurement of mechanical properties}

The cylindrical samples were subjected to uniaxial compression on a mechanical testing machine (Instron, Model 4005). Each sample was placed between parallel compression plates. Sellotape, affixed to the ends of the sample, acted as a lubricant between the sample and the platens, also holding the ends of the samples together after fracturing. The conditions of testing were: crosshead speed of $5 \mathrm{~mm} / \mathrm{min}, 100 \mathrm{kN}$ load-cell, normal room temperature and humidity. The elastic modulus in compression was calculated from the slope of the linear portion of load-displacement curve and the dimensions of the sample. The compressive strength was calculated as the ratio of the maximum load sustained by the sample divided by the cross-sectional area.

\section{EXPERIMENTAL RESULTS}

Figure 1 shows recordings obtained on the unmixed raw materials, clearly identifying the minerals as pure kaolin, quartz and goethite. X-ray diffraction of bodies A and B (not shown) gave complex diffraction patterns indicating the presence of the three main constituents, i.e. kaolin, quartz and orthoclase feldspar. This conclusion is supported by the work of Chi (1996). Quantitative estimation of 


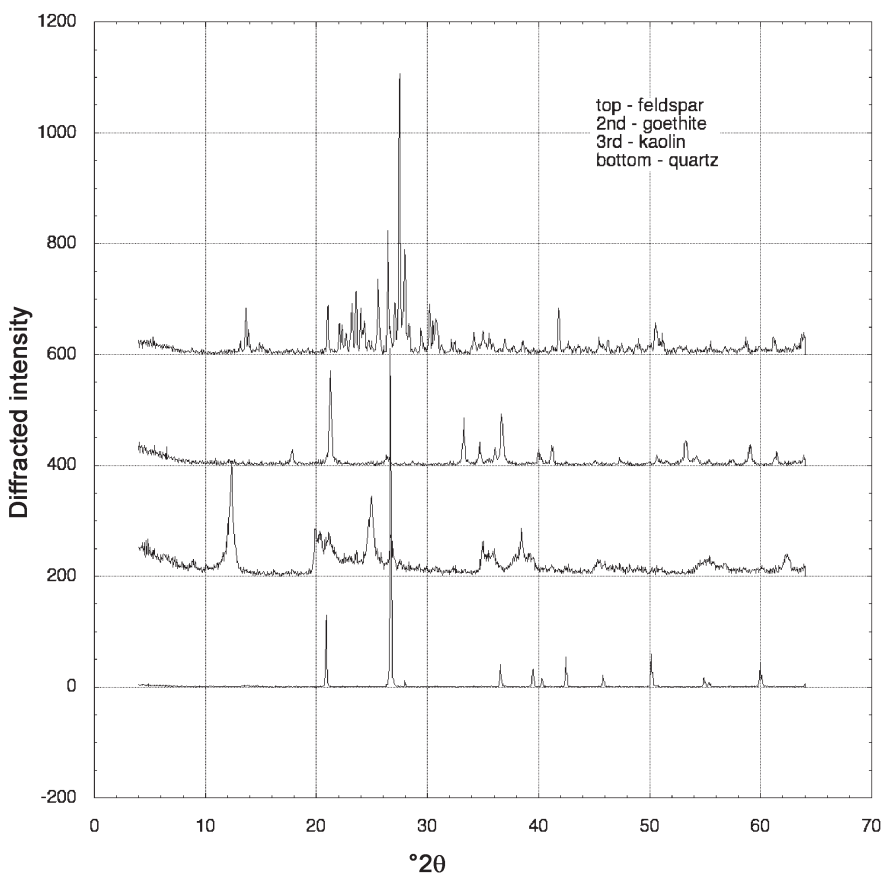

FIG. 1. XRD patterns of three minerals used in the ceramic clay bodies. Goethite appeared in body B only. $(\mathrm{Cu}-\mathrm{K} \alpha$ radiation, powder samples.)

the components was not attempted due to the uncertainty of the process.

Figure 2 shows the composite distribution of particle sizes measured on the as-received bodies by the two different techniques as described earlier. Significant differences can be observed at the finest particle end, and between $\sim 50$ and $350 \mu \mathrm{m}$ equivalent spherical diameter range.
Micrographs from cut and polished surfaces of samples from bodies $\mathrm{A}$ and $\mathrm{B}$, fired to all indicated temperatures, were obtained by scanning electron microscopy (SEM). Figures 3 and 4 show SEM images for selected samples fired to 1000,1260 and $1320^{\circ} \mathrm{C}$, respectively. The thin sections were coated by carbon sputtering and the images obtained in back-scattered mode.

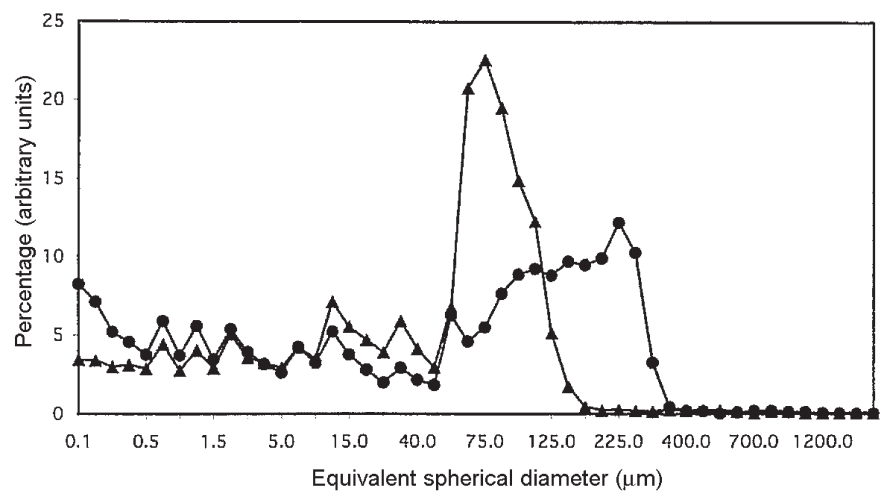

FIG. 2. Distribution of particle sizes in the stoneware clay bodies, derived from measurements carried out using SediGraph 5100 and a Column sediments analyser. Note the differences at the lowest fractions and significant differences for fractions between 50 and $350 \mu \mathrm{m}$. 

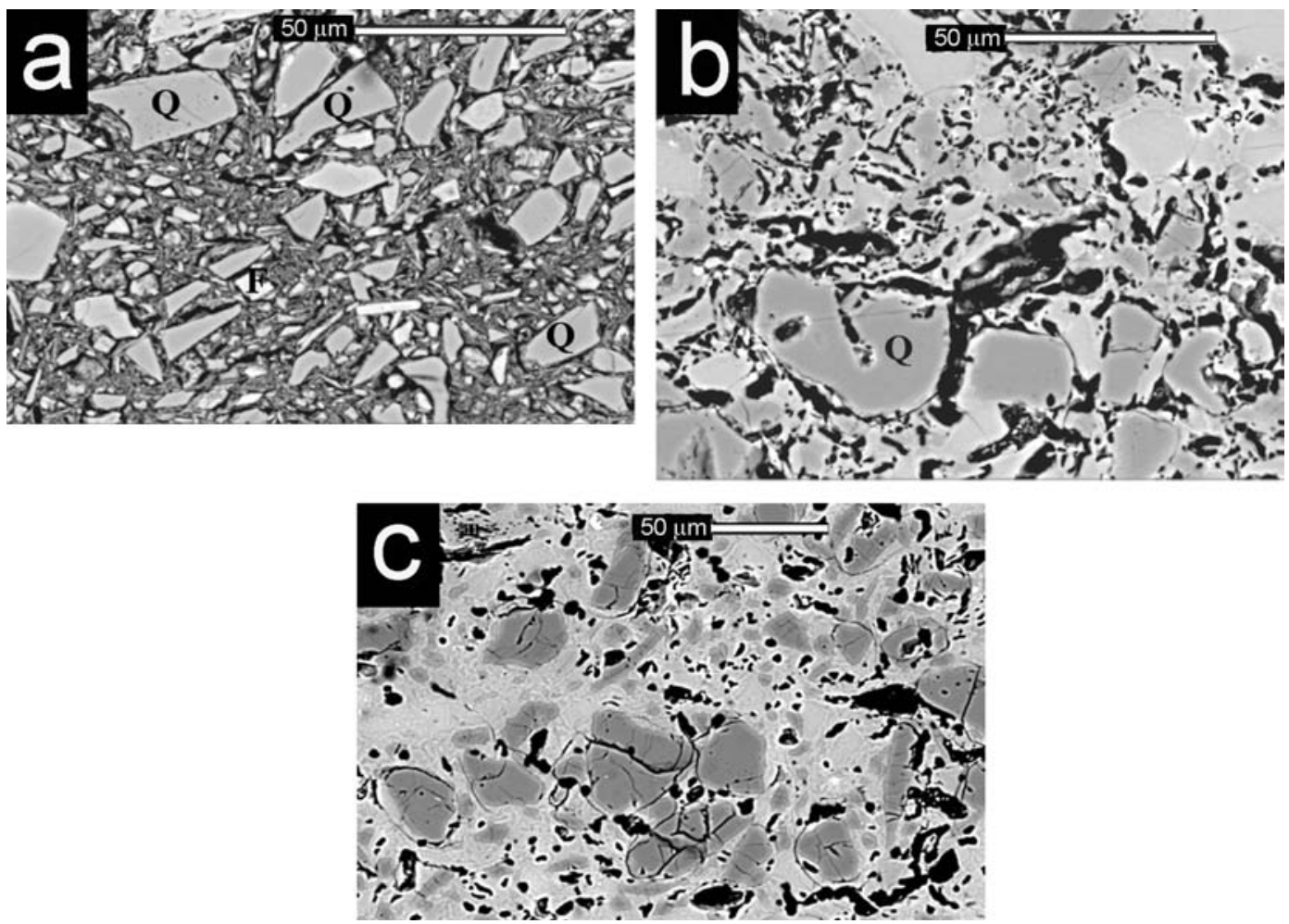

FIG. 3. SEM images of stoneware body A fired to approximately: (a) $1000^{\circ} \mathrm{C}$, (b) $1180^{\circ} \mathrm{C}$, and (c) $1320^{\circ} \mathrm{C}$. SEM backscattered mode from polished thin sections. In (a) a feldspar grain is indicated by $\mathrm{F}$. The large grey particles are quartz grains (some identified by Q). Scale bar $=50 \mu \mathrm{m}$.

The results of physical measurements carried out in the course of this study are shown in Figs 5-8. Each point on the graphs represents an average of five individual measurements. Figure 5 shows the changing volume of the samples over the firing temperature range. It can be observed that the volume decreases monotonically for both. However, it is interesting to note that Body B, although prepared in exactly the same way as Body A, showed greater shrinkage on drying as indicated by the lower starting value at $1000^{\circ} \mathrm{C}$, whereas its subsequent decrease in volume on firing was in parallel with the other. This is consistent with the initial apparent porosity being higher for Body B than for Body A, which we think reflects variation with particle-size distribution.

Figure 6 shows the variation of the apparent porosity with firing temperature. It varies from close to $19 \%$ at the initial firing temperature, down to $\sim 2 \%$ at the highest firing temperature. The decrease in apparent porosity is seen to occur over three stages: (1) a relatively fast change from 1000 to $1180^{\circ} \mathrm{C}$; (2) an arrest between $\sim 1180$ and $1260^{\circ} \mathrm{C}$; (3) a final stage which is again relatively fast. Associated with apparent porosity and volume is the apparent density (not shown), starting at the low value of $\sim 1.8 \mathrm{~g} / \mathrm{cm}^{3}$, and increasing to $\sim 2.3 \mathrm{~g} /$ $\mathrm{cm}^{3}$, consistent with the changes in volume shrinkage and apparent porosity.

Figure 7 shows the variation of the elastic modulus with firing temperature. Again, three regions of behaviour can be distinguished: (1) up to $\sim 1180^{\circ} \mathrm{C}$ where the elastic modulus increases rapidly; (2) between 1180 and $1260^{\circ} \mathrm{C}$ where the modulus remains to a first approximation constant; and (3) beyond $1260^{\circ} \mathrm{C}$, the final region, surprisingly characterized by a gradual loss of mechanical elasticity. Figure 8 shows the variation of compressive strength with firing temperature measured in the same test as the elastic modulus. Here three stages of dependence on firing temperature are also evident. 

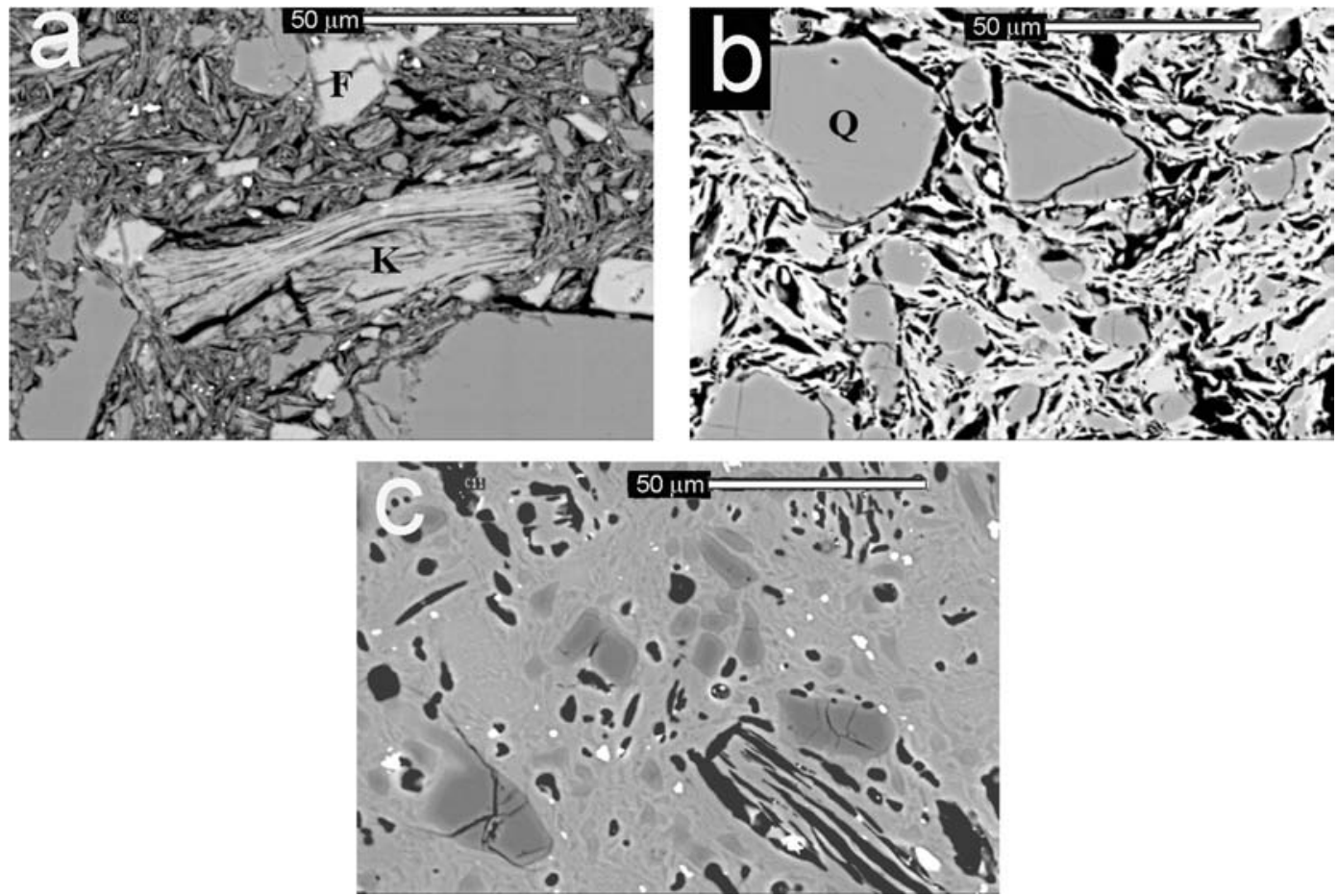

FIG. 4. SEM images of stoneware body B fired to approximately: (a) $1000^{\circ} \mathrm{C}$, (b) $1180^{\circ} \mathrm{C}$, and (c) $1320^{\circ} \mathrm{C}$. SEM backscattered mode from polished thin sections. The large grey particles are quartz (Q). Part (a) shows a large particle $(\mathrm{K})$ with dickite-like morphology, and feldspar particles $(\mathrm{F})$ as identified by XRD. White particles in (c) (infrequently observed) give indications, under SEM probe, of tin or zircon, and must be original inclusions in the raw materials. Scale bars $=50 \mu \mathrm{m}$.

\section{DISCUSSION}

\section{Microstructure}

The changes in microstructure, seen in Fig. $3 a-c$ for Body A, and Fig. $4 \mathrm{a}-\mathrm{c}$ for Body B, represent characteristic points of three significant stages in the development of microstructures in the stoneware clay bodies:

(1) up to $\sim 1180^{\circ} \mathrm{C}$,

(2) from $\sim 1180$ to $1260^{\circ} \mathrm{C}$, and

(3) above $\sim 1260$ to $1320^{\circ} \mathrm{C}$.

These changes are the result of phase transformations, as well as melting and eutectic formations that take place increasingly in stage 2, and continuously in stage 3 . Initial reactions (dehydration of minerals and driving out of volatiles) are completed by $\sim 600^{\circ} \mathrm{C}$ (Sosman, 1965; Deer et al., 1992). In this temperature range, kaolin transforms to metakaolin with slight shrinkage and an increase in porosity (Kingery et al., 1976). By $\sim 980^{\circ} \mathrm{C}$, metakaolin decomposes into spinel and reactive
$\mathrm{SiO}_{2}$ (Brindley \& Lemaitre, 1987). The original particles appear to be held together at numerous but small contact points (assumed to result from sintering) so that the compressive strength reaches $\sim 40 \mathrm{MPa}$ as shown in Fig. 8. The original distribution and morphology of the particles are still preserved (these microstructures are very similar to those reported in Fig. 2 of Bauluz et al. (2004), who report that there is little glass formation at this temperature, although the differences in mineral composition must be noted). The micrographs in Figs $3 \mathrm{a}$ and $4 \mathrm{a}$ show close similarities in microstructures: voids are almost all uniformly small; larger voids are associated with margins of much larger particles; individual particle boundaries are obvious and clearly defined; and there is no observable aggregation of particles as a consequence of melting. Noticeable in Body B are large laminar kaolin particles (Fig. 4a). The most obvious feature that distinguishes Body A from Body $\mathrm{B}$ is the difference in size and distribution of 


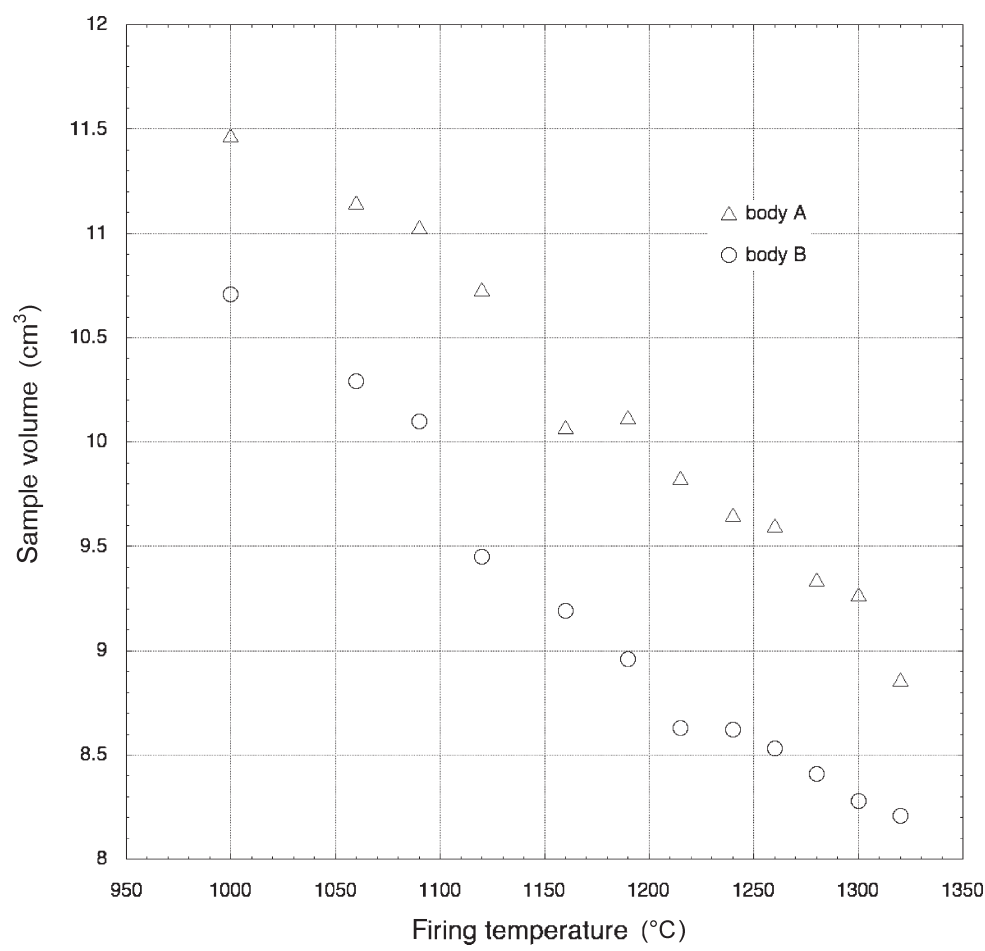

FIG. 5. Variation of measured sample volume over the whole firing range. Note that stoneware body B, although prepared in exactly the same way as the other, shows greater shrinkage on drying, whereas its subsequent decrease in volume on firing was in parallel with stoneware body A. Each point is an average of five samples.

particles within the range of 50 to $350 \mu \mathrm{m}$ (Fig. 2). The different types of voids observed include articulated voids that are a direct consequence of the irregular contact points between particles of differing shapes and sizes, and both sealed and articulated voids that are inherent in the raw materials introduced into the clay bodies.

As can be seen in Figs $3 b$ and $4 b$, further changes take place at increasing temperatures. At $\sim 1100^{\circ} \mathrm{C}$, feldspar melts, leading to the formation of glasses in combination with $\mathrm{SiO}_{2}$ evolving from metakaolin, reacting with quartz grains to melt outer surfaces and sharp corners, forming an inhomogeneous glassy matrix (Smith \& Brown, 1988). Above $1150^{\circ} \mathrm{C}$, orthoclase feldspar transforms to leucite and $\mathrm{SiO}_{2}$, adding further to the glassy matrix of varying composition. According to Deer et al. (1992), and Wyatt and Dew-Hughes (1974), quartz transforms to cristobalite at $1470^{\circ} \mathrm{C}$. However, Heany et al. (1995) reported that cristobalite can be metastable well below this temperature. Simultaneously, porosity is correspondingly reduced. This is already visible in micrographs shown in Figs $3 b$ and $4 b$, where large particles and voids are rounded off, small particles have fused together, and micropores have to a large degree disappeared. Thin cracks appear around large particles as a consequence of the above-mentioned transformations with accompanying volumetric changes. Small particles ranging between 1 and $5 \mu \mathrm{m}$ that were clearly observable in each of the stoneware clay bodies in Figs $3 \mathrm{a}$ and $4 \mathrm{a}$ are no longer present. Particles of $>10 \mu \mathrm{m}$ are surrounded by fused aggregations containing larger and less evenly distributed voids. Voids larger than those contained in, and associated with, the surrounding solid continue to be associated with large particle boundaries. There is evidence of cracking in large-particle boundary/small-void interfaces as well as transverse cracking in elongated large particles.

At the highest firing temperature $\left(\sim 1320^{\circ} \mathrm{C}\right)$, a complex glassy matrix, variegated in appearance, seen in Figs $3 c$ and $4 c$, is the dominant phase of the microstructure, occupying a greater proportion in Body B than in Body A. It is assumed to be glassy 


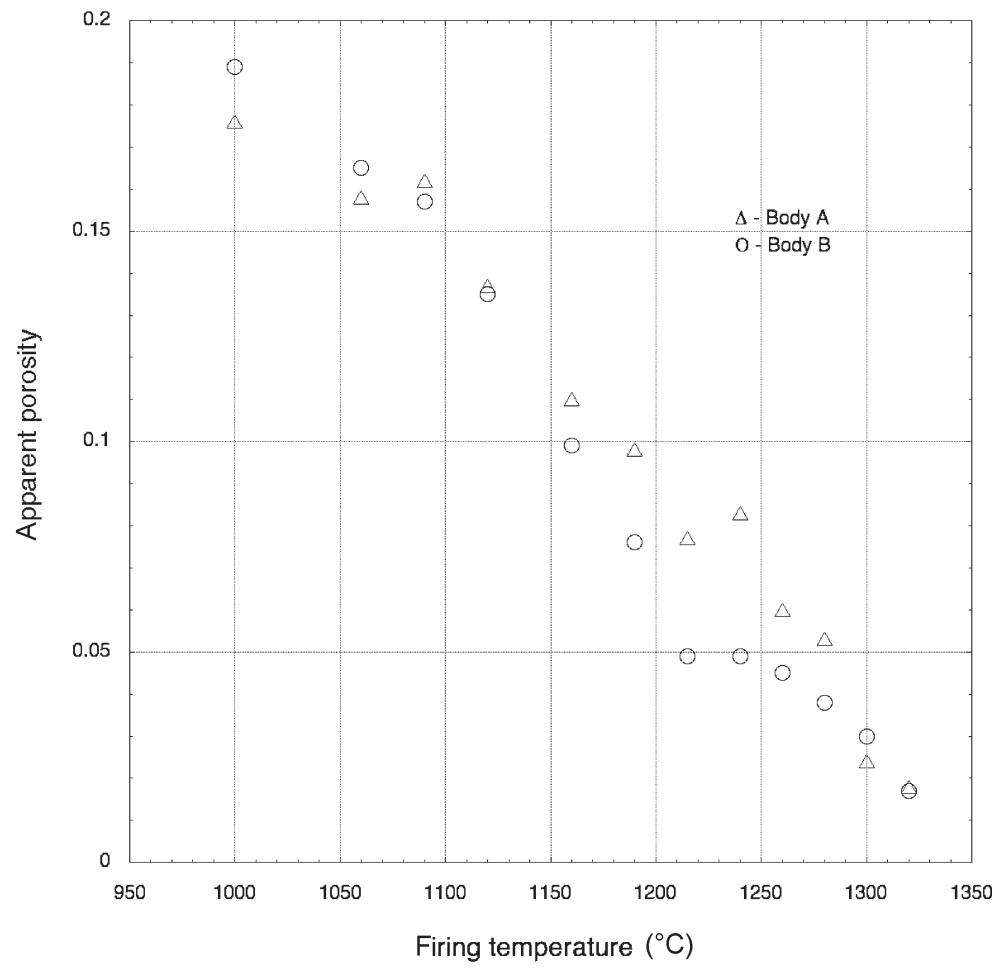

FIG. 6. Variation of measured apparent porosity over the whole firing range. Stoneware body B shows greater decrease of open porosity on firing between $1180^{\circ}$ and $1260^{\circ} \mathrm{C}$ than stoneware body A. Each point is an average of five samples.

since XRD gives a broad scattering peak with small sharper peaks that must arise from the remaining crystalline phases. The larger extent of vitrification in Body $\mathrm{B}$ is likely to be the result of the small additions of the $\mathrm{Fe}$ oxide. The other major phase comprises silica (quartz particles), clearly identifiable under SEM analytical probe, and some grains also identified in the micrographs. The interface between the remaining silica particles and the matrix is diffuse and in many places cracked. Porosity has decreased considerably, and it is not evident which part consists of open voids, and which of sealed voids, now approximately in equal proportions. Cracks are evident around the grains as well as within the grains, as reported by Menéndez et al. (1996). We assume the cracks have formed on cooling from the firing temperature due to differential shrinkage. Changes in the size and distribution of voids are less obvious than in the earlier micrographs. Body B contains elongated voids ( $\sim 50 \mu \mathrm{m}$ long), which originated from the kaolin particles as can be seen in Fig. 4 a.

\section{Porosity and density}

We have estimated the sealed porosity by making use of equation 9. Figure 9 shows the variation of open porosity, as derived from apparent porosity, and the calculated sealed porosity. For each body, the sum of open and sealed porosities gives the total porosity. The finer details, evident in the two bodies, are ascribed to differences in particle-size distribution and the associated rate of formation of eutectics and sintering. The sudden increase in sealed porosity at $\sim 1180^{\circ} \mathrm{C}$ suggests onset of melting and fusion leading to closure of previously articulated voids. The calculations required the knowledge of solid density as defined by equation 3 , which can be estimated using equation 10 . We have been able to determine that the silica-rich phase is quite pure and can be identified as quartz (Fig. 1). From Sosman (1965) and Heaney et al. (1995) we take the density of the initial quartz constituent as $2.65( \pm 0.01) \mathrm{g} / \mathrm{cm}^{3}$. On firing to high temperature $\left(1300^{\circ} \mathrm{C}\right)$, quartz can convert to 


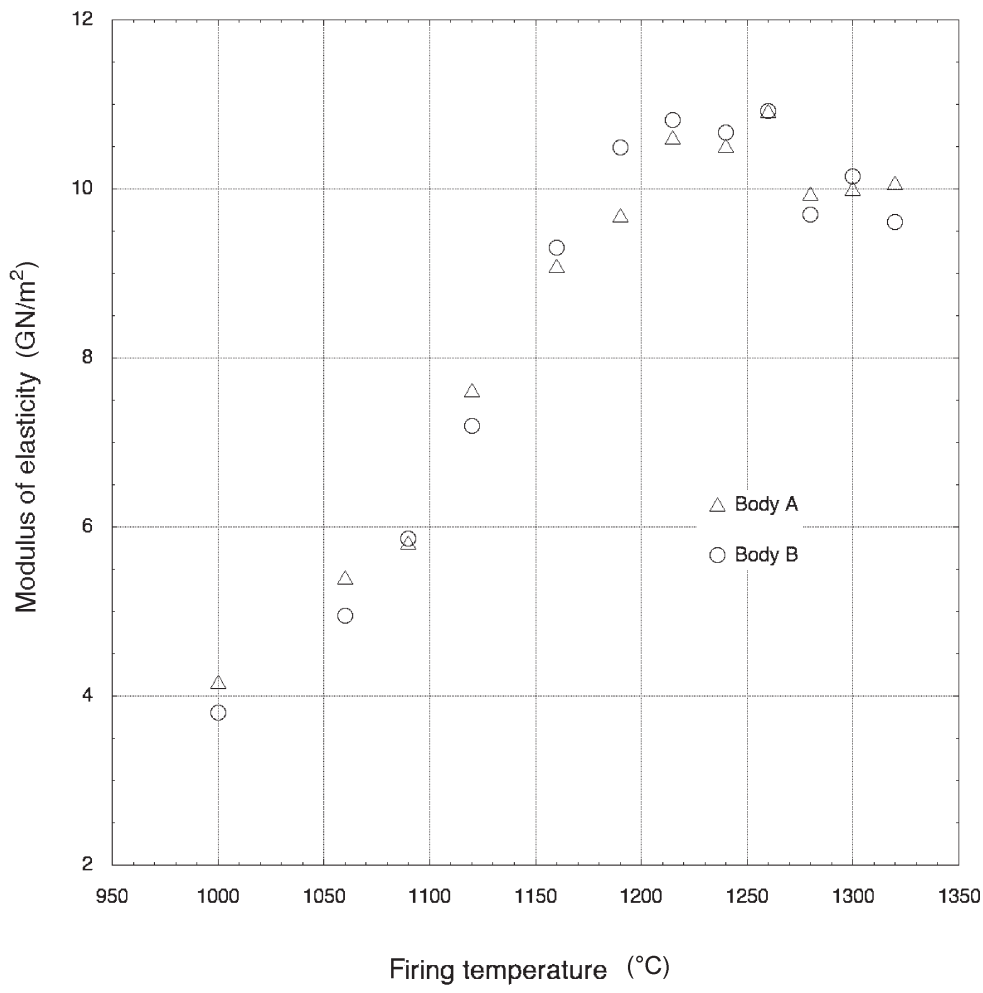

FIG. 7. Variation of measured elastic modulus in compression over the whole firing range. Note the decrease observed after $1260^{\circ} \mathrm{C}$, due to the formation of inhomogeneous glasses and circumferential cracks around silica particles. Each point is an average of five samples.

cristobalite with a corresponding reduction in density (Smith \& Brown, 1988) which can be as low as $2.35 \mathrm{~g} / \mathrm{cm}^{3}$. The feldspars used in these compounds are K-rich, orthoclase minerals. This has been confirmed by XRD, and during SEM observations. We take the density of the initial constituent as $2.58( \pm 0.02) \mathrm{g} / \mathrm{cm}^{3}$ (Deer et al., 1992; Smith \& Brown, 1988). In the temperature rage of 1120 to $1180^{\circ} \mathrm{C}$, feldspars melt forming a glassy phase of variable density, which we estimate as $2.38( \pm 0.02) \mathrm{g} / \mathrm{cm}^{3}$. The structure and properties of Australian kaolin minerals have been studied thoroughly by Chi (1996). The density of the kaolin from Victorian fields is taken as $2.64( \pm 0.02)$ $\mathrm{g} / \mathrm{cm}^{3}$. On firing, kaolin transforms gradually to metakaolin to spinel, forming mullite as well as contributing to glass formation of density $\sim 2.38 \mathrm{~g} / \mathrm{cm}^{3}$.

We have calculated the solid density of both stoneware clay bodies after the first firing as 2.629 $( \pm 0.025) \mathrm{g} / \mathrm{cm}^{3}$. It is assumed to be constant between 1000 and $1180^{\circ} \mathrm{C}$. The next step required estimation of the variation of densities with higher firing temperatures. We noted from SEM observation of thin sections, and from XRD results, that at the highest-temperature $\left(1320^{\circ} \mathrm{C}\right)$ feldspars have fused with kaolin, and that approximately a third of the quartz has also fused with surrounding constituents. At the same time XRD traces indicated an increase in the $\mathrm{X}$-ray amorphous (glass) content from insignificant at $1000^{\circ} \mathrm{C}$, to $\sim 40 \%$ at the final firing at $1320^{\circ} \mathrm{C}$. We assume the volume fraction of glass to be 0.4 , and its density to be $2.38 \mathrm{~g} / \mathrm{cm}^{3}$. The volume fraction of the transformed and recrystallized materials is 0.6 ; therefore, the final solid density of the bodies is estimated to be 2.51 $( \pm 0.03) \mathrm{g} / \mathrm{cm}^{3}$. It is assumed that it decreases monotonically between 1180 and $1320^{\circ} \mathrm{C}$.

Volume shrinkage is evidence for reduction in porosity, and this information was used by Zhang et al. (1944) to corroborate their measurements of permeability during hot isostatic pressing of mineral 


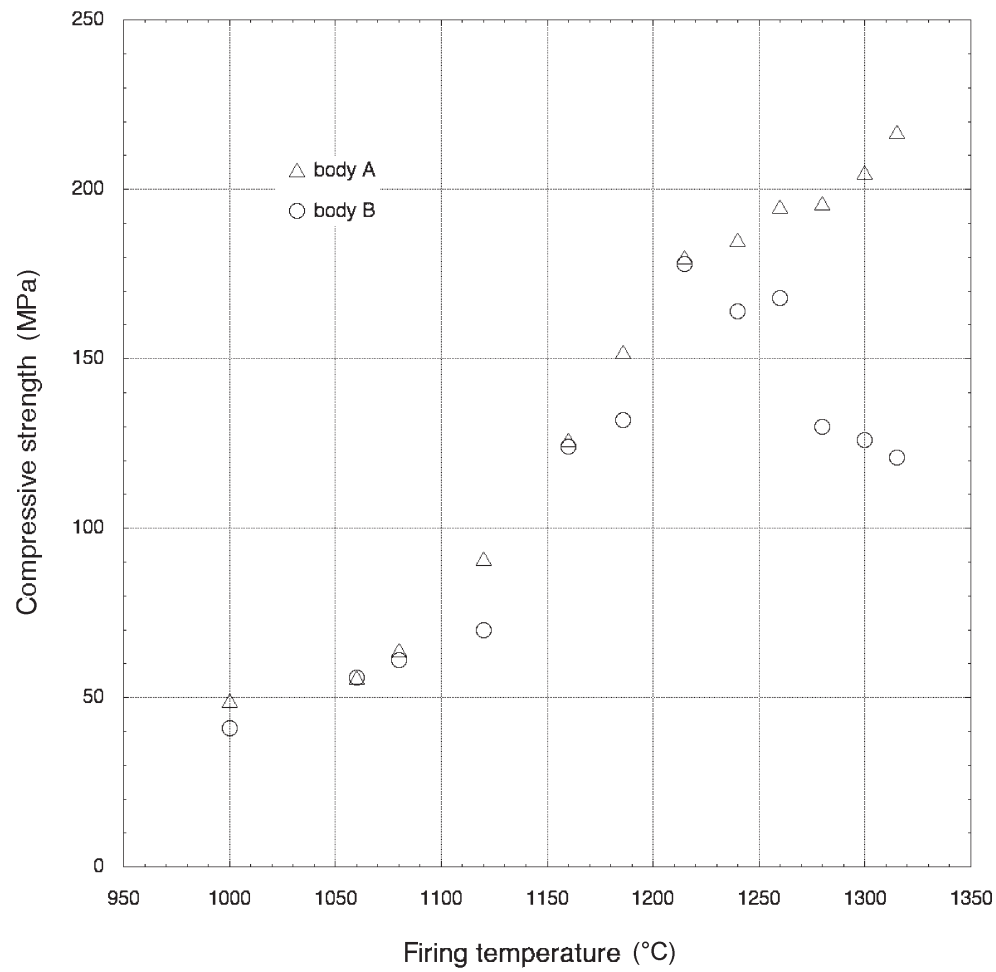

FIG. 8. Variation of compressive strength of the two stoneware clay bodies A and B over the whole firing range. Body B is weaker as the firing temperature increases. Each point is an average of five samples.

aggregates. We have already used this information in equation 9 to derive sealed porosity. Other methods for porosity measurement could have been applied but were deemed to be unnecessary as the results reported here are consistent with densification behaviour reported for other aggregate bodies. For instance, in the above-mentioned work (Zhang et al., 1944), the porosity of the aggregate starts at $\sim 0.22$ and ends at 0.06 after isostatic hot pressing. The total porosity measured for Bodies $\mathrm{A}$ and $\mathrm{B}$ is also around that value after firing to $1300^{\circ} \mathrm{C}$ (slightly higher because densification occurred as a result of sintering forces alone without the aid of isostatic pressing). By contrast, the greater initial porosity value of $\sim 0.32$ for bodies $\mathrm{A}$ and $\mathrm{B}$, is ascribed to the presence of introduced inherent porosity, as evident in the micrographs in Figs 3a and $4 \mathrm{a}$.

\section{MECHANICAL PROPERTIES}

The effective value of the modulus of the composite was estimated using equation 11. For this we need the moduli of individual components: for quartzite, $E=55( \pm 20)$ GPa (Brindley \& Lemaitre, 1987; Jumikis, 1979), for feldspar, $E=45( \pm 20) \mathrm{GPa}$. Kaolin shows both strong anisotropy and some internal porosity; we take the value of $15( \pm 10) \mathrm{GPa}$ as a reasonable average value. Allowing for the uncertainty in the volume fraction of the components, the effective modulus of the stoneware clay bodies is calculated to be $30( \pm 15) \mathrm{GPa}$. No allowance for porosity has been made. Therefore this value corresponds to an isotropic composite at zero porosity. At $1000^{\circ} \mathrm{C}$, porosity is of the order of $35 \%$, and the much lower value of $\sim 4 \mathrm{GPa}$ was found by experimental measurements (Fig. 7). As the absolute porosity and its variation have been calculated, one can analyse the experimental data from Fig. 7 using equations 12 and 13. A plot of the experimental values against porosity factors is shown in Fig. 10, where it can be seen that extrapolation towards zero porosity of the trend shown by the first $4-5$ points is close to $35 \mathrm{GPa}$, well within the above-calculated range of the effective modulus at zero porosity. The result for 


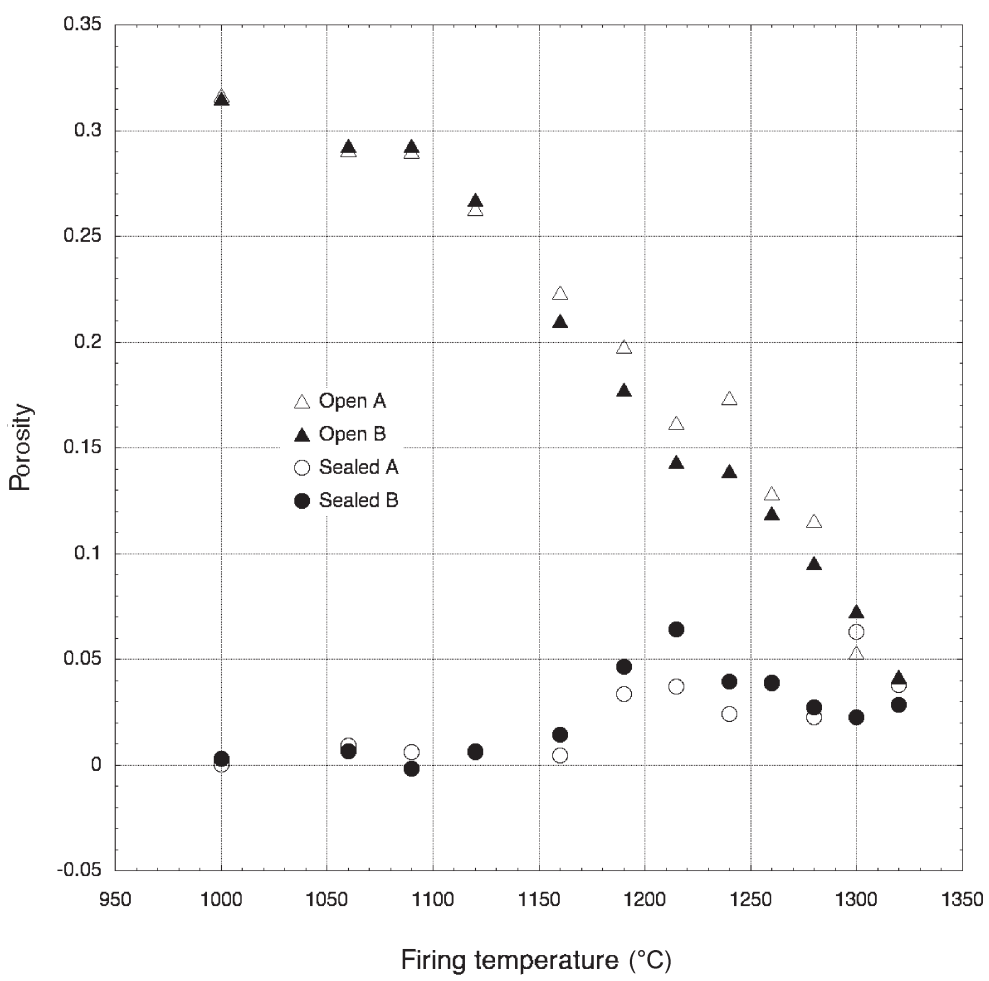

FIG. 9. Calculated open and sealed porosity over the whole firing range. Open porosity (open triangles - Body A, open circles - Body B) calculated from equation 4, and sealed porosity (filled triangles - Body A, filled circles - Body B) calculated from equation 9.

Body B is very similar. This analysis predicts the modulus of both fired stoneware clay bodies at zero porosity to be in the range $25-35 \mathrm{GPa}$.

For samples fired beyond $1180^{\circ} \mathrm{C}$ the elastic modulus appears not to be affected by variations in porosity, even though total porosity continues to decrease. The modulus reaches peak values of close to $12 \mathrm{GPa}$ between 1180 and $1260^{\circ} \mathrm{C}$, and then, for firings at the highest temperatures employed, decreases slightly to $\sim 10 \mathrm{GPa}$ instead of rising to near $35 \mathrm{GPa}$ as predicted in Fig. 10. We ascribe this remarkable phenomenon to two factors: (1) the chemical changes occurring in the composite bodies; and (2) the formation of circumferential cracks around the remaining silica particles. The first factor is the formation of eutectics and glassy phases resulting in a lower modulus than that of original feldspars, and the second is the decoupling of silica particles from the matrix by the cracks. We propose that both contribute simultaneously to lower the elastic response of the materials.
Assuming a value of 0.5 for the friction coefficient, and solving equation 15 for critical crack length, gives:

$$
a_{\mathrm{c}} \cong 2.5 \frac{G_{\mathrm{Ic}} \times E}{\left(\sigma_{\mathrm{f}}\right)^{2}}
$$

Figure 11 shows the variation of the critical crack size as a function of firing temperature for the two stoneware clay bodies, assuming a typical value of $G_{\text {Ic }}=20 \mathrm{~J} / \mathrm{m}^{2}$ for ceramics, and using the modulus and strength values from Figs 7 and 8 . The graph shows some similarity to the graph for open porosity with firing temperature (Fig. 9), suggesting that the pores play the role of the critical crack. The size of the pores decreases with decreasing porosity (increasing firing temperature) as is evident from the micrographs. The compressive fracture strength of the samples increases correspondingly as the critical crack size reduces from $\sim 100 \mu \mathrm{m}$ at the initial firing temperature to $20 \mu \mathrm{m}$ at $1200^{\circ} \mathrm{C}$. Above $1260^{\circ} \mathrm{C}$, the formation of micro-eutectics at 


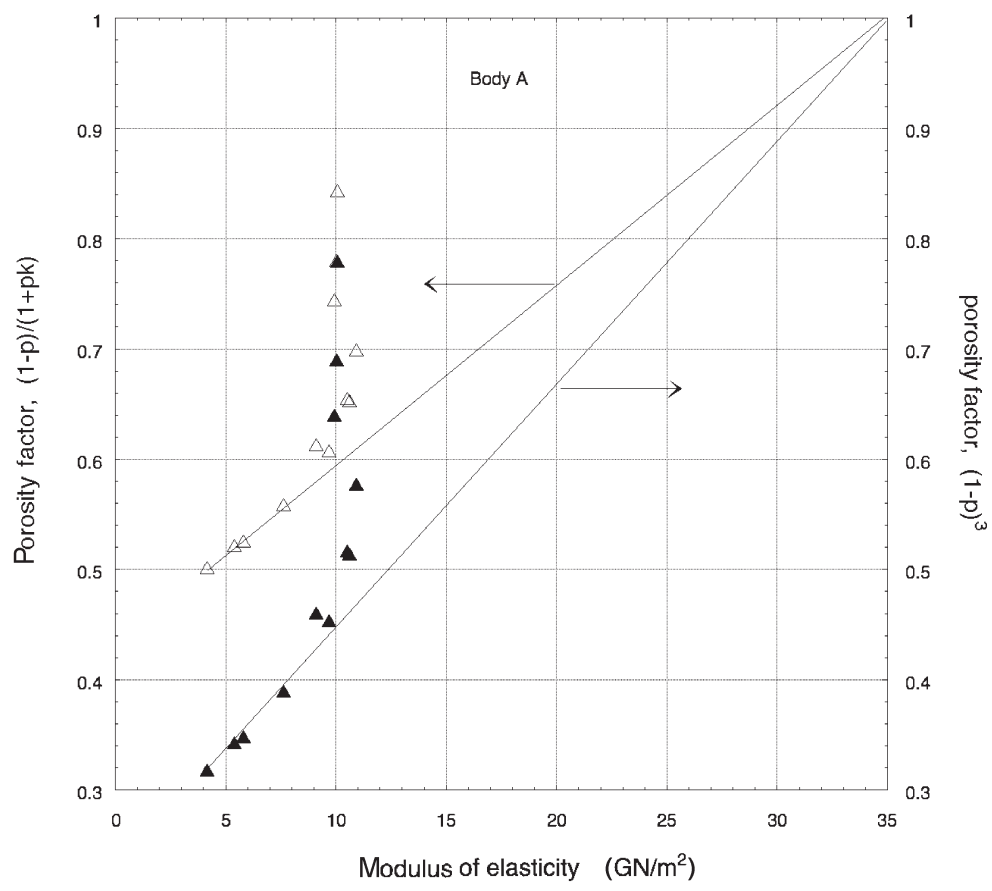

FIG. 10. Analysis of the variation of elastic modulus with porosity for stoneware body A in terms of equations 12 and 13. Extrapolation to zero porosity points to a value of $\sim 35 \mathrm{GPa}$, in agreement with calculations described in the text.

contact points leads to localized melting and glass formation on cooling. Differential thermal shrinkage causes cracks to appear around the large particles. This has a significant effect on Body B since it contains larger particles, the shrinkage cracks contribute to lowering of its fracture strength at the high firing temperatures. Interestingly, Body A continues to increase in strength even at the higher firing temperatures. Tentatively, we ascribe this different behaviour to the differences in particle-size distributions, which is the subject of a separate study.

\section{CONCLUSIONS}

The absolute porosity of the stoneware clay samples drops continuously from $\sim 0.33$ at first firing at $1000^{\circ} \mathrm{C}$ to $\sim 0.08$ after the final firing at $1300^{\circ} \mathrm{C}$. Initially, the porosity appears as connected open voids only, changing to both sealed and open porosity, each comprising a $\sim 0.04$ fraction at the final firing. This continuous densification of the material is not mirrored by a corresponding increase in elastic modulus. The modulus of elasticity of the samples, whilst primarily determined by the solid constituents, is also influenced by the presence of pore/voids and microcracks. The modulus-porosity relationship is not described adequately by the existing physical models.

The micromechanics of compressive failure in stoneware clay bodies appears to be related to porosity in that the critical crack size for failure initiation decreases with decreasing void size. However, above $\sim 1260^{\circ} \mathrm{C}$ the simple relationship does not appear to hold for Body B, where the compressive strength reverses its trend, contrary to that of porosity. Since Body B contains a larger amount of particles in the $100-300 \mathrm{~mm}$ size, it leads us to the tentative conclusion that shrinkage cracks forming around these particles lower the fracture strength of these fired stoneware clays.

\section{ACKNOWLEDGMENTS}

The authors gratefully acknowledge assistance given by Dr Sally Stowe and the staff of the ANU Electron Microscope Unit for their invaluable instruction in the 


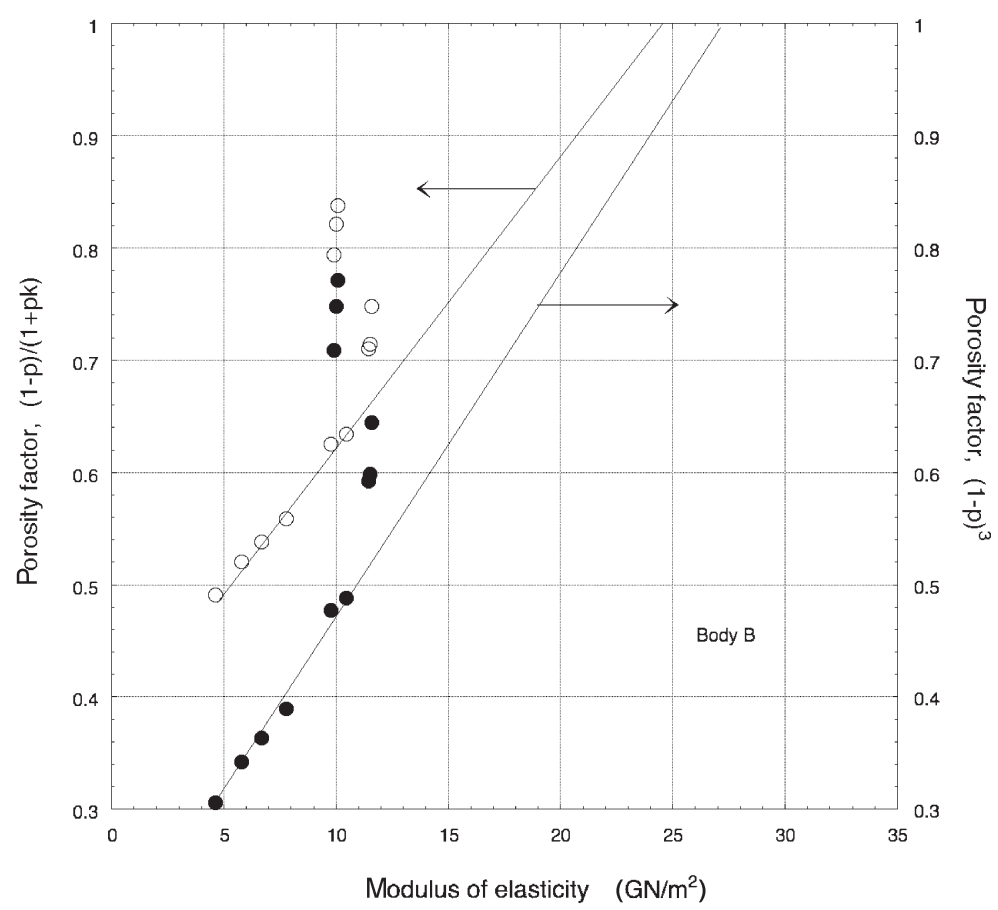

FIG. 11. Predicted variation of critical crack size (using equation 16) for compression fracture of the stoneware clay bodies, assuming a constant strain energy release rate of $20 \mathrm{~J} / \mathrm{m}^{2}$, and using the experimental values of modulus and compressive strength from Figs 7 and 8 .

use of their instruments and assistance in imaging. We also wish to thank Dr Meta Sterns of the Department of Chemistry for X-ray diffraction of the samples, and the Geology Department, ANU, for the preparation of thin sections for microscopy, and helpful discussions regarding the interpretation of some microstructural features. All firings in this program were carried out in kilns in the Ceramics Workshop, Faculty of the Arts, ANU. We are also grateful to the AGSO for the use of their particle-size analysis equipment.

\section{REFERENCES}

Ashby M.F. \& Hallam S.D. (1986) The failure of brittle solids containing small cracks under compressive stress states. Acta Metallurgica, 34, 497-510.

Bauluz B., Mayayo M.J., Yuste A., Fernandez-Nieto C. \& Gonzalez Lopez J.M. (2004) TEM study of mineral transformations in fired carbonated clays: relevance to brick making. Clay Minerals, 39, 333-344.

Brandt R.C. Hasselman D.P.H. \& Lange F.F. (eds) (1978) Fracture Mechanics of Ceramics, Vol. 4, Plenum Press, New York.

Brindley G.W. \& Lemaitre J. (1987) Thermal, oxidation and reduction reactions of clay minerals. Pp.
319-370 in: Chemistry of Clays and Clay Minerals (A.C.D. Newman, editor). Monograph No. 6, Mineralogical Society, London.

Chi M.A. (1996) The ultra-structure of kaolin. PhD thesis, Australian National University, Menzies Library, Canberra.

Deer W.A., Howie R.A. \& Zussman J. (1992) An Introduction to the Rock-Forming Minerals. Longman Scientific \& Technical, London.

Heaney P.J., Prewitt C.T. \& Gibbs G.V., editors (1995) Silica: Physical Behaviour, Geochemistry and Materials Applications. Reviews in Mineralogy, 29, Mineralogical Society of America, Washington, D.C.

Helmuth R.A. \& Turk D.H. (1966) Highway Research Board. National Research Council (US) Special Report 90, 135-141.

Holliday L. (1967) Composite Materials. Elsevier, London, p. 16.

Jumikis A.R. (1983) Rock Mechanics. Trans Tech Publications, New Jersey. p. 94.

Kendal K. (1978) Complexities of compression failure. Proceedings of the Royal Society of London, A362, 245-263.

Kingery W.D., Bowden H.K. \& Uhlmann D.R. (1976) Introduction to Ceramics, $2^{\text {nd }}$ edition. John Wiley \& Sons, New York.

Kunori T. \& Geil P.H. (1980) Morphology-property 
relationships in polycarbonate-based blends: I. Modulus. Journal of Macromolecular Science Physics, B18(1), 118-175.

Menendez B., Zhu W. \& Wong T.-F. (1996) Micromechanics of brittle faulting and cataclastic flow in Berea sandstone. Journal of Structural Geology, 18, 1-16.

Orton E., Jr., Ceramic Foundation (1994) The use of pyrometric cones. Westerville, Ohio, USA. Interceram, 43(2), 107.

Sammis C.G. \& Ashby M.F. (1986) The failure of brittle porous solids under compressive stress states. Acta Metallurgica, 34, 511-526.

Singer F.S. \& Singer S.S. (1971) Industrial Ceramics.
Chapman \& Hall, London.

Smith J.V. \& Brown W.L. (1988) Feldspar Minerals: Crystal Structures, Physical, Chemical and Microtextural Properties. Vol. 1, Chapter 12, Springer-Verlag, Berlin.

Sosman R.B. (1965) The Phases of Silica. Rutgers University Press, New Brunswick, Canada, p. 11.

Wyatt O.H. \& Dew-Hughes D. (1974) Metals, Ceramics and Polymers. Cambridge University Press, Cambridge, UK, p. 227.

Zhang S., Patterson M.S. \& Cox S.F. (1994) Porosity and permeability evolution during hot isostatic pressing of calcite aggregates. Journal of Geophysical Research, 99/B8, 15,741-15,760. 